\title{
ChemComm
}

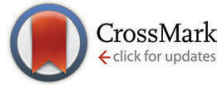

Cite this: Chem. Commun., 2016, 52,8448

Received 30th March 2016

Accepted 7th June 2016

DOI: $10.1039 / c 6 c c 02693 a$

www.rsc.org/chemcomm

\section{Preparation of difluoromethylthioethers through difluoromethylation of disulfides using $\mathrm{TMS}^{-} \mathrm{CF}_{2} \mathrm{H} \dagger$}

\author{
Joseph L. Howard, Christiane Schotten, Stephen T. Alston and Duncan L. Browne*
}

\begin{abstract}
We report an operationally simple, metal-free approach for the late-stage introduction of the important lipophilic hydrogen-bond donor motif, $\mathrm{SCF}_{2} \mathrm{H}$. This reaction converts diaryl- and dialkyl-disulfides into the corresponding aryl/alkyl- $\mathrm{SCF}_{2} \mathrm{H}$ through the nucleophilic transfer of a difluoromethyl group with good functional group tolerance. This method is notable for its use of commercially available $\mathrm{TMSCF}_{2} \mathrm{H}$, and does not rely on the need for handling of sensitive metal complexes.
\end{abstract}

The fluorination of organic molecules continues to lead to materials with improved properties with which to fuel our modern society. As testament to the dramatic improvements available by the fluorination of organic materials, recent years have seen a growth, at the discovery phase, of a late-stage fluorine scanning approach. ${ }^{1}$ Such an approach looks to fine-tune physicochemical properties by the inclusion of fluorine atoms. ${ }^{2}$ Whilst some effects of fluorination can be rationally predicted and thus provide a toolbox to guide fine-tuning, several key observations have not been predictable, but have lead to exciting new observations for organo-fluorine chemistry. ${ }^{3}$ It is perhaps owing to this rich-seam of uncharted beneficial effects that the synthesis community are increasingly interested in organo-fluorine methods. In contrast to this late-stage approach however, there is now increasing pressure to reduce the amount of fluorinated waste materials making it into waste streams and eventually in to the ecosystem. Especially given that degradation of fluorous compounds through standard biological processes is greatly retarded by nature's poor ability to process fluorinated materials. ${ }^{4}$ As a fine balance between this dichotomy we are interested in developing rationally designed methods for late stage fluorination approaches to under-represented fluorous motifs. Herein our particular focus has been on the series consisting of fluorinated methylthioethers R-SCF $\mathrm{H}_{(3-x)}$ (Fig. 1). Initially we considered the $x=0$ state; methylthioethers. This motif is rarely present in

School of Chemistry, Cardiff University, Main Building, Park Place, Cardiff, CF10 3AT, UK. E-mail: dlbrowne@cardiff.ac.uk

$\dagger$ Electronic supplementary information (ESI) available. See DOI: 10.1039/c6cc02693a properties of thioethers and fluorous congeners - R-SCF $\mathrm{H}_{(3-\mathrm{x})}$

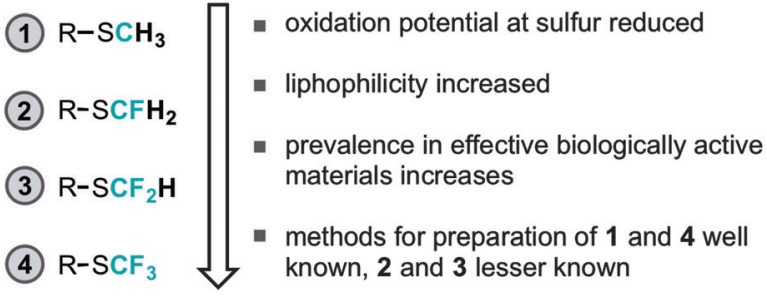

Fig. 1 Effect of fluorine addition on thioethers.

biologically active materials, owing to a poor metabolic profile characterised by oxidation at sulfur by cytochromes (such as P450). The resultant sulfoxides/sulfones are then more easily cleared before the target is reached. Notably, stable sulfoxides and sulfones are not uncommonly found in biologically active materials. ${ }^{5}$ Assessment of the fully fluorinated variant; $x=3$ state, highlights several examples of this motif present in successful-tomarket biologically active materials. ${ }^{6}$ From an electronics perspective the sulfur atom in this case is more electron deficient (than in the $x=0$ case) so the rate of oxidation through a nucleophilic at sulfur mechanism is greatly reduced (comparatively), resulting in reduced metabolism and reduced clearance levels. This leads to an ability for these molecules to reach the intended target before being metabolically cleared. This is however an over simplified view as the $c \log P$ or liphophilicity of $\mathrm{SCF}_{3}$ is also different (greater) from that of $\mathrm{SCH}_{3} .{ }^{7}$ Increased lipophilicity manifests in to a number of phenomena, not the least of which include less specific binding to enzymes and better transport across the blood:brain barrier. Regarding the $x=2$ state, the $\mathrm{SCF}_{2} \mathrm{H}$ motif maintains many of the properties displayed by $\mathrm{SCF}_{3}$, but, in addition, gains hydrogen-bond donor capabilities. Thus $\mathrm{SCF}_{2} \mathrm{H}$ essentially serves as a lipophilic hydrogen-bond donor motif for drug discovery, however the range of methods for the preparation of this motif are relatively narrow (compared to $\mathrm{SCF}_{3}$ ).

The most commonly explored approach to the $\mathrm{SCF}_{2} \mathrm{H}$ motif features the in situ generation of difluorocarbene followed by nucleophilic attack from a thiol or thiolate and protonation of 
carbene approaches

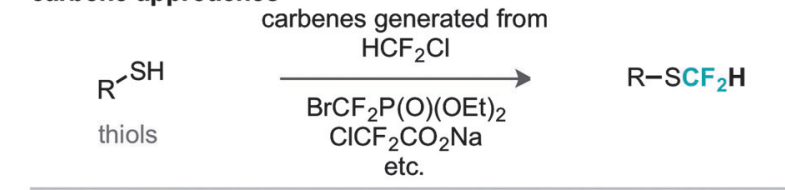

electrophilic approach (transition metal free)

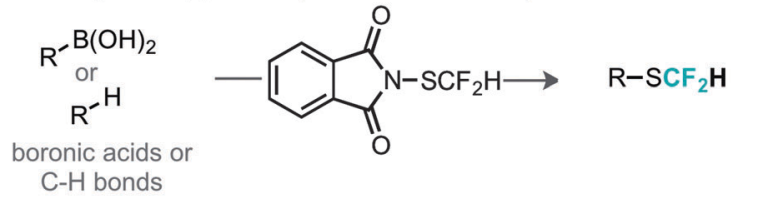

$\mathrm{C}-\mathrm{H}$ bonds

nucleophilic approach (metal mediated)
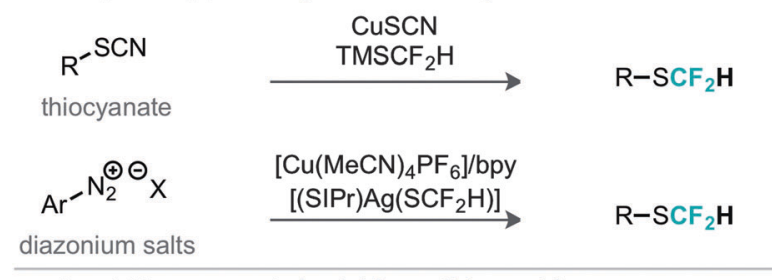

nucleophilic approach (metal free - this work)

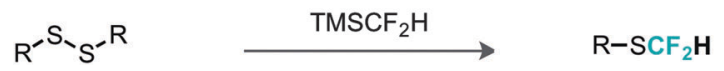

Scheme 1 Synthetic routes to difluoromethylthioethers.

the resulting difluoromethide (Scheme 1$).{ }^{8}$ With increasing attention in this moiety there have been recent examples of methods developed for its late stage introduction. For example an electrophilic strategy was reported, whereby $N$-difluoromethylthiophthalimide was demonstrated for the direct difluoromethylthiolation of a range of nucleophilic substrates such as boronic acids and aromatic $\mathrm{C}-\mathrm{H}$ bonds. ${ }^{9}$ Shen has also developed a metal mediated nucleophilic protocol for the conversion of aromatic diazonium salts in to the corresponding aryl- $\mathrm{SCF}_{2} \mathrm{H}$ compounds using $\left[(\mathrm{SIPr}) \mathrm{Ag}\left(\mathrm{SCF}_{2} \mathrm{H}\right)\right]$ as the $\mathrm{SCF}_{2} \mathrm{H}$ source. $^{10}$

An alternative copper mediated approach was reported for the conversion of thiocyanates or aryl diazonium salts using $\mathrm{TMSCF}_{2} \mathrm{H}^{11}$ Our approach was to develop an operationally simple method, whereby transfer of the required fluorinated carbon unit from a silicate complex to a disulfide electrophile would result in formation of the difluoromethylthioether. Indeed, during the course of our studies, very recently Zhang, Zhu and co-workers published on an identical strategy. ${ }^{12}$ Notably an analogous approach exists for trifluoromethylation of disulfides as reported by Langlois. ${ }^{13}$ In this instance the Ruppert-Prakash reagent, activated by fluoride from TBAF was shown to transfer to the corresponding benzylic disulfides in good yield. It was noted that aromatic disulfides offer poor conversion under these conditions with a single example reported (Scheme 2). For the difluoromethylthioether we initially commenced by simply repeating this approach with $\mathrm{TMSCF}_{2} \mathrm{H}$. Under these conditions, a poor conversion of $14 \%$ was found and a control experiment in our hands highlighted that the work of Langlois was perfectly reproducible. This observation suggested that the lower conversion for $-\mathrm{CF}_{2} \mathrm{H}$ variants is inherent in the
Experimental Observations

- trifluoromethylation of disulphides using $\mathrm{TMSCF}_{3}$

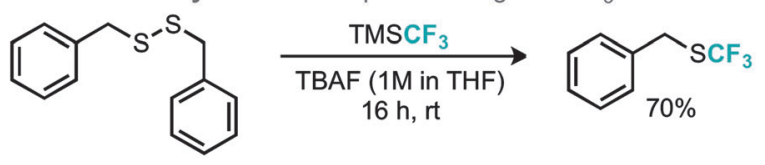

- difluoromethylation of disulphides using $\mathrm{TMSCF}_{2} \mathrm{H}$
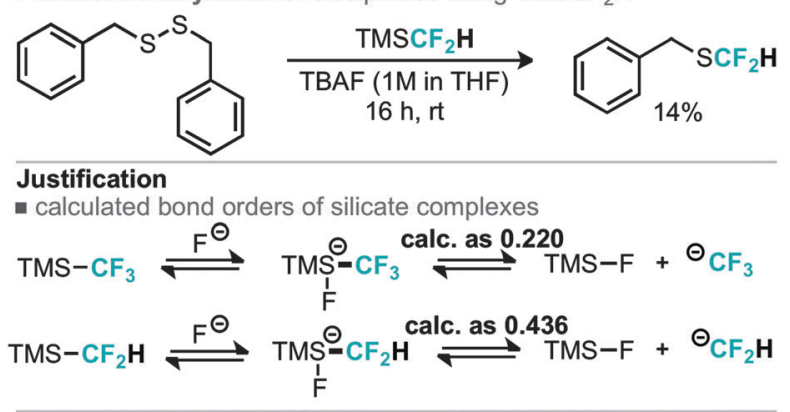

Hypothesis

- destabilise silicate and/or stabilise anion through optimisation of activating agent and solvent choice

Scheme 2 Project design and hypothesis.

reactivity of these species. Indeed a report from Fuchikami describes the stability of both the $\mathrm{TMSCF}_{3}$ and the $\mathrm{TMSCF}_{2} \mathrm{H}$ fluoro-silicate complexes. ${ }^{14}$ Notably the authors calculate that the bond order (a reflection on the ion formation potential) for $\mathrm{TMSCF}_{3}$ was approximately half that of $\mathrm{TMSCF}_{2} \mathrm{H}$, at 0.220 , implying that the difluoromethylsilicate complex was less prone to generating the required difluoromethyl anion species. We hypothesised that appropriate choice of activating agent and solvent could help to destabilise the silicate complex and/or stabilise the desired ion formation, which would lead to improved nucleophile transfer. Our studies commenced by treating a solution of dibenzyldisulfide and $\mathrm{TMSCF}_{2} \mathrm{H}$ in THF with a range of activating agents (Table 1). Notably a range of fluoride sources, $t$-BuOK (previously shown to effectively activate $\mathrm{TMSCF}_{2} \mathrm{H}$ ), ${ }^{15}$ and a combination of either of these with copper(I) salts failed to provide much conversion to the desired product. Upon switching to different solvents, it was found that simple fluoride sources could perform the required activation with CsF out-performing $\mathrm{KF}$ in both acetonitrile and $N, N$-dimethylacetamide ( $c f$. entries 7 , 8 and entries 9, 10, Table 1). Indeed, further solvent probing with CsF highlighted $N$-methylpyrrolidine as optimal, affording the desired product in $63 \%$ conversion. An increase in reaction temperature resulted in a poorer reaction yield, (Table 1 , entry 14, 36\%). Optimal conditions were reached by increasing the equivalents of $\mathrm{TMSCF}_{2} \mathrm{H}$ and CsF further (entry 18, $82 \%$ yield). With optimal conditions in hand for the metal-free nucleophilic difluoromethylation of dibenzyldisulfide we then turned attention to the generality of the scope of this method with respect to dialkyldisulfides. We evaluated several methods for the reliable and rapid synthesis of disulfide starting materials and found treatment of thiols with inexpensive dibromodimethylhydantoin to be the most effective. ${ }^{16}$ Pleasingly, a range of dibenzyldisulfides underwent the difluoromethylation reaction to provide the products in good yield (Scheme 3), including the ortho-bromo derivative 3 ( $73 \%$ yield). Non-benzylic substrates also participated 
Table 1 Optimisation of reaction conditions

activating agent (equiv)
solvent
rt, 16 h

in the reaction, including secondary alkyl disulfides, with the cyclopentyl variant 5 proceeding in 34\% yield. Free alcohols are also amenable under the present methodology, with the difluoromethylthioether 6 undergoing reaction in 49\% yield. However, in stark contrast to the trifluoromethylation approach reported by Langlois, the present method of difluoromethylation was highly effective on diaryldisulfides. As shown in Scheme 4, diaryldisulfides convert to the desired fluorinated products with good to excellent conversion. Both electron rich and electron poor examples proceed well, as do ortho-substituted systems and heteroaromatics, with a 2-pyridyl example converting to the $\mathrm{SCF}_{2} \mathrm{H}$ product (17) in $49 \%$ yield. Notably, whilst we have proven that isolation and accurate depiction of isolated yields is somewhat hampered by compound volatility, we believe that the late stage fluorination of more advanced drug-like scaffolds

$$
\text { (Het)Aryl }(\mathrm{Het}) \mathrm{Aryl} \text { - } \mathrm{SCF}_{2} \mathrm{H}
$$

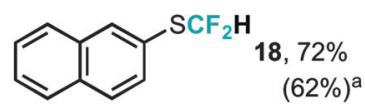

Scheme 4 Reaction scope for diaryldisulfides. ${ }^{a}$ Isolated yield. ${ }^{17}$

(higher molecular weight) would permit ready isolation of the $\mathrm{SCF}_{2} \mathrm{H}$ material as testament to this compounds $\mathbf{1 0}$ and 18 have been found to be isolable. ${ }^{17}$

In summary, we report conditions for the preparation of a range of difluoromethylthioethers from their corresponding disulfide starting materials. The reported method is operationally simple, metal-free and uses commercially available fluorinating agents. The method is applicable to a range of dialkyldisulfides and diaryldisulfides and is tolerant to a range of functionalities, including free alcohols and pyridine nitrogens.

We thank the School of Chemistry, Cardiff University for generous support, Fluorochem for kind donations of $\mathrm{TMSCF}_{2} \mathrm{H}$ and the EPSRC UK National Mass Spectrometry Facility at Swansea University for mass spec data.

\section{Notes and references}

1 For some overviews in the area of organofluorine chemistry see: (a) C. N. Neumann and T. Ritter, Angew. Chem., Int. Ed., 2015, 54, 3216; (b) I. Hyohdoh, N. Furuichi, T. Aoki, Y. Itezono, H. Shirai, S. Ozawa, F. Watanabe, M. Matsushita, M. Sakaitani, P. S. Ho, K. Takanashi, N. Harada, Y. Tomii, K. Yoshinari, K. Ori, M. Tabo, Y. Aoki, N. Shimma and H. Iikura, ACS Med. Chem. Lett., 2013, 4, 1059; (c) T. Furuya, C. A. Kuttruff and T. Ritter, Curr. Opin. Drug Discovery Dev., 2008, 11, 803; (d) J. Wang, M. Sánchez-Roselló, J. L. Aceña, C. del Pozo, A. E. Sorochinsky, S. Fustero, V. A. Soloshonok and H. Liu, Chem. Rev., 2014, 114, 2432; (e) J.-P. Bégué and D. Bonnet-Delpon, J. Fluorine Chem., 2006, 127, 992; $(f)$ K. L. Kirk, Org. Process Res. Dev., 2008, 12, 305; $(g)$ S. Purser, P. R. Moore, S. Swallow and V. Gouverneur, Chem. Soc. Rev., 2008, 37, 320; (h) W. K. Hagmann, J. Med. Chem., 2008, 51, 4359; (i) N. A. Meanwell, J. Med. Chem., 2011, 54, 2529; (j) D. T. Wong, K. W. Perry and F. P. Bymaster, Nat. Rev. Drug Discovery, 2005, 4, 764; (k) X.-H. Xu, K. Matsuzaki and N. Shibata, Chem. Rev., 2015, 115, 731; (l) P. Jeschke, ChemBioChem, 2004, 5, 570; $(m)$ K. Müller, 
C. Faeh and F. Diederich, Science, 2007, 317, 1881; (n) L. M. Yagupol'skii, A. Y. Il'chenko and N. V. Kondratenko, Russ. Chem. Rev., 1974, 43, 32; (o) D. L. Browne, Synlett, 2015, 33; (p) T. Liang, C. N. Neumann and T. Ritter, Angew. Chem., Int. Ed., 2013, 52, 8214; (q) J.-A. Ma and D. Cahard, Chem. Rev., 2004, 104, 6119.

2 (a) B. E. Smart, J. Fluorine Chem., 2001, 109, 3; (b) M. Morgenthaler, E. Schweizer, A. Hoffmann-Röder, F. Benini, R. E. Martin, G. Jaeschke, B. Wagner, H. Fischer, S. Bendels, D. Zimmerli, J. Schneider, F. Diederich, M. Kansy and K. Müller, ChemMedChem, 2007, 2, 1100; (c) R. Filler and R. Saha, Future Med. Chem., 2009, 1, 777; (d) D. B. Berkowitz and M. Bose, J. Fluorine Chem., 2001, 112, 13; (e) D. O'Hagan, J. Fluorine Chem., 2010, 131, 1071.

3 (a) K. Müller, C. Faeh and F. Diederich, Science, 2007, 317, 1881; (b) M. Schlosser, Angew. Chem., Int. Ed., 1998, 110, 1496; (c) A. Bondi, J. Phys. Chem., 1964, 68, 441; (d) J. D. Dunitz and R. Taylor, Chem. Eur. J., 1997, 3, 89.

4 (a) B. D. Key, R. D. Howell and C. S. Criddle, Environ. Sci. Technol., 1997, 31, 2445; (b) D. O'Hagan, C. Schaffrath, S. L. Cobb, J. T. G. Hamilton and C. D. Murphy, Nature, 2002, 416, 279; (c) G. W. Gribble, Naturally Occurring Organofluorines, in Handbook of Environmental Chemistry, ed. A. H. Neilson, Springer-Verlag, Berlin, vol. 3, part N, 2002.

5 (a) X. Chen, S. Hussain, S. Parveen, S. Zhang, Y. Yang and C. Zhu, Curr. Med. Chem., 2012, 19, 3578; (b) R. Bentley, Chem. Soc. Rev., 2005, 34, 609.

6 (a) V. N. Boiko, Beilstein J. Org. Chem., 2010, 6, 880; (b) J. F. Giudicelli, C. Richer and A. Berdeaux, Br. J. Clin. Pharmacol., 1976, 3, 113; (c) M. Diaferia, F. Veronesi, G. Morganti, L. Nisoli and D. P. Fioretti, Parasitol. Res., 2013, 112, 163.

7 C. Hansch, A. Leo, S. H. Unger, K. H. Kim, D. Nikaitani and E. J. Lien, J. Med. Chem., 1973, 16, 1207.

8 (a) J. Hine and J. J. Porter, J. Am. Chem. Soc., 1960, 82, 6118;

(b) P. Deprez and J. P. Vevert, J. Fluorine Chem., 1996, 80, 159;

(c) Y. Zafrani, G. Sod-Moriah and Y. Segall, Tetrahedron, 2009,
65, 5278; (d) K. Fuchibe, M. Bando, R. Takayama and J. Ichikawa, J. Fluorine Chem., 2015, 171, 133; (e) V. P. Mehta and M. F. Greaney, Org. Lett., 2013, 15, 5036; ( $f$ ) G. K. Surya Prakash, S. Krishnamoorthy, S. Kar and G. A. Olah, J. Fluorine Chem., 2015, 180, 186; $(g)$ W. Zhang, J.-M. Zhu and J.-B. Hu, Tetrahedron Lett., 2008, 49, 5006; (h) Y. Fujiwara, J. A. Dixon, R. A. Rodriguez, R. D. Baxter, D. D. Dixon, M. R. Collin, D. G. Blackmond and P. S. Baran, J. Am. Chem. Soc., 2012, 134, 1494; (i) W. Zhang, F. Wang and J. Hu, Org. Lett., 2009, 11, 2109; $(j)$ G. K. Surya Prakash, Z. Zhang, F. Wang, C.-F. Ni and G. A. Olah, J. Fluorine Chem., 2011, 132, 792; (k) L.-C. Li, F. Wang, C.-F. Ni and J.-B. Hu, Angew. Chem., Int. Ed., 2013, 52, 12390.

9 D. Zhu, Y. Gu, L. Lu and Q. Shen, J. Am. Chem. Soc., 2015, 137, 10547. 10 J. Wu, Y. Gu, X. Leng and Q. Shen, Angew. Chem., Int. Ed., 2015, $\mathbf{5 4}, 7648$.

11 (a) B. Bayarmagnai, C. Matheis, K. Jouvin and L. J. Gooßen, Angew. Chem., Int. Ed., 2015, 54, 5753; (b) K. Jouvin, C. Matheis and L. J. Gooßen, Chem. - Eur. J., 2015, 21, 14324; (c) C. Matheis, M. Wang, T. Krause and L. J. Gooßen, Synlett, 2015, 1628; (d) G. Danoun, B. Bayarmagnai, M. F. Gruenberg and L. J. Gooßen, Chem. Sci., 2014, $5,1312$.

12 During the preparation of this manuscript, we became aware of the work of J.-B. Han, H.-L. Qin, S.-H. Ye, L. Zhu and C.-P. Zhang, J. Org. Chem., 2016, 81, 2506.

13 T. Billard and B. R. Langlois, Tetrahedron Lett., 1996, 37, 6865.

14 T. Hagiwara and T. Fuchikami, Synlett, 1995, 717.

15 (a) Y. Zhao, W. Huang, J. Zheng and J. Hu, Org. Lett., 2011, 13, 5342;

(b) P. S. Fier and J. F. Hartwig, J. Am. Chem. Soc., 2012, 134, 5524.

16 See the ESI $\dagger$ for details of this method adapted from A. Khazaei, M. A. Zolfigol and A. Rostami, Synthesis, 2004, 2959.

17 Isolated by a counter-current style extraction and column chromatography, see the ESI $\dagger$ for details. Value of 'isolated yield' proven to be largely subjective owing to the volatility of these compounds, ${ }^{19} \mathrm{~F}-\mathrm{NMR}$ with an internal standard provides a less subjective measure of reaction performance. 